\title{
THE PRESENT POSITION OF THE TREATMENT OF MEGALOBLASTIC ANAEMIAS
}

\author{
By C. C. Ungley, M.D., F.R.C.P. \\ Physician, Royal Victoria Infirmary, Newcastle upon Tyne
}

A distinction must be drawn between megaloblastic and macrocytic anaemias. Not all macrocytic anaemias are megaloblastic and not all megaloblastic anaemias are macrocytic.

The term macrocytosis refers to the size of red blood cells in the peripheral blood. The mean cell volume of packed red blood cells (haematocrit) may be greater than normal, or the diameters of a proportion of red blood cells may fall outside the normal limits of Price-Jones' curves. Macrocytosis may be present even when the marrow does not contain megaloblasts, e.g. sometimes in diseases of the liver and in leukaemias.

Macrospherocytosis - i.e. increase in mean volume of red blood cells without a corresponding increase in their mean diameter and may also exist without a megaloblastic marrow, e.g. in some acquired haemolytic anaemias.

Megaloblastic anaemias are distinguished in two ways:

(a) by finding megaloblasts within the peripheral blood or in the marrow

(b) by therapeutic tests with cyanocobalamin (vitamin $B_{12}$ ) or folic acid.

\section{The Bone Marrow}

The megaloblast is not merely an early red cell; it is morphologically abnormal because of deficiency of either cyanocobalamin or folic acid. The abnormality disappears from the marrow within a few days of commencing therapy with the appropriate agent.

The most diagnostic cell is the Erlich megaloblast. This retains an immature finely stippled nucleus even when haemoglobin has appeared in the cytoplasm. Earlier, less mature, megaloblasts may be difficult to distinguish from non-haemoglobinised precursors of the normoblast or macronormoblastic series. Mature, fully haemoglobinised cells with a pyknotic nucleus are less diagnostic than the Erlich megaloblast.

Megaloblasts may occasionally be found in the peripheral blood, especially if smears are made from the buffet coat (white cell-platelet layer) of a centrifuged specimen.

Other characteristics of the marrow in megaloblastic anaemias are its cellularity (although this may be difficult to assess in a smear obtained by marrow puncture), and the presence of abnormal precursors of the neutrophil series-large myelocytes and metamyelocytes.

In the peripheral blood in Addisonian pernicious anaemia the mean cell volume is usually over 100 cubic microns. Oval megalocytes may be present. The Price-Jones curve shows a shift to the right due to such cells. In some other types of megaloblastic anaemia (e.g. in pregnancy or sprue) the mean cell diameter and the mean cell volume may be normal or even less than normal. Leucocytes, especially polymorphs, may be diminished. Polymorphs with an abnormally large number of lobes are present, i.e. the Arneth count shows a shift to the right. There may also be macropolycytes. The platelets may be few in number and abnormally variable in size and shape.

It is important to recognise that the manifestations of cyanocobalamin deficiency, e.g. in the tongue or the nervous system, may exist even before there are haematological changes in the blood or the marrow. Estimation of serum cyanocobalamin is helpful in such cases.

\section{Varieties of Megaloblastic Anaemia}

Megaloblastic anaemia is a manifestation of deficiency of cyanocobalamin or of folic acid or of both these agents. Dietary deficiency of one or both factors is a feature in some tropical megaloblastic anaemias. Vegans who consume no animal proteins of any kind may suffer from the effects of deficiency of cyanocobalamin.

Deficient absorption of cyanocobalamin in Addisonian pernicious anaemia and after gastrectomy is due to lack of Castle's intrinsic factor which is secreted by the corpus region of the 
stomach. Absorption of cyanocobalamin or folic acid may be deficient in some forms of sprue or steatorrhoea and after some lesions of, or operations on, the stomach and intestine.

Increased requirements for, or an abnormal metabolism of, anti-megaloblastic substances may occur in pregnancy.

Certain agents used for the treatment of epilepsy may interfere with the metabolism of folic acid or cyanocobalamin.

The fish tapeworm takes up cyanocobalamin and may cause megaloblastic anaemia if situated high in the small intestine, where it can compete with its host for a supply of this agent.

\section{Early Diagnosis and Management of Megalo- blastic Anaemias}

It is a mistake to give anti-megaloblastic substances first, and send the patient for diagnosis afterwards. Even if the marrow was originally megaloblastic, it may not revert to this state for weeks, months or even years, even if therapy is discontinued. It is probably an error to treat the ' anaemia' even with iron before a diagnosis has been established. A tragic example may be cited. A detective-sergeant became pale in February and without a blood examination was given an 'iron tonic.' He improved rapidly and went on working. On holiday in August he felt unwell again and a specimen of his blood was sent to a local hospital. The report was equivocal and a trial of cyanocobalamin was suggested. When this failed the patient was sent to a physician interested in haematology. The anaemia was hypochromic and occult blood was detected on rectal examination. Operation revealed carcinoma of the transverse colon already involving the peritoneum. The patient died four months later.

This story emphasises the importance of early diagnosis. In this region we now invite practitioners to send patients to hospital before commencing anti-anaemic therapy-even iron, and blood examination can be performed immediately if necessary.

The first step is to measure the haemoglobin, in fact some practitioners in the area measure this themselves. If the Tallqvist method is used patients with haemoglobin of 90 per cent. or over can be excluded. But some patients with a haemoglobin of 70 per cent. Tallqvist prove not to be anaemic when a more accurate method is used. If the patient proves to be anaemic a cause is sought. Most of the anaemias are of an iron deficiency type, due to heavy menstrual losses, poor diet or to bleeding from the alimentary tract.

If the history and physical signs lead to a suspicion of deficiency of cyanocobalamin or folic acid, e.g. if there is a suspicion of megaloblastic anaemia, a full blood count and haematocrit is performed and marrow puncture and gastric analysis if indicated, and tests for serum cyanocobalamin and serum iron. Stools are tested for occult blood.

If the marrow is megaloblastic the patient is admitted to hospital for a therapeutic test. Dietary control is desirable to reduce the intake of haematinic factors such as are present in meat and fruit. Cyanocobalamin 100 to $250 \mu \mathrm{g}$. may be given first. A reticulocyte response will show that the patient is responding, but not the degree of effect. A better way of assessing the rate of blood regeneration is to measure the increase of red blood cells and packed cell volume in 15 days (Ungley and Campbell, r949 and unpublished).

If the cyanocobalamin is not effective a single dose of folic acid may be given. When the reticulocytosis subsides and when the marrow reverts to megaloblastic another single dose of cyanocobalamin may be tried. Sometimes the latter becomes effective after a temporary need for folic acid has been met.

For a patient who is very ill or has severe heart failure, exchange transfusion of packed red blood cells from a pint $(580 \mathrm{ml}$.) of blood may be given.

If there is diarrhoea or malabsorption it is worth sorting out the nature of the deficiency causing the megaloblastic anaemia by giving serial therapeutic tests. Sometimes there is a deficiency of folic acid which is temporary; after a single dose of folic acid the patient may remain well during maintenance therapy with cyanocobalamin. In other cases only folic acid is needed. Patients with permanent achlorhydria or low serum cyanocobalamin values should be treated with cyanocobalamin in addition to folic acid.

\section{Diagnosis of Folic Acid Deficiency}

Malabsorption of folic acid may be detected by the method of Girdwood (1956). First the patient is saturated with folic acid by injected doses. Then oral and injected doses are given on alternate days. If there is malabsorption the amount of folic acid excreted in twenty-four hours is much less after oral than after intra-muscular administration of a similar dose.

This test for the oral : injection ratio is useful for the detection of malabsorption of folic acid. There is not, however, a satisfactory method at present for detecting folic acid deficiency. The results of microbiological assays of blood and urine with Lactobacillus leichmannii and Leuconostoc citrovorum show wide variations both in patients and in normal individuals. Even patients who respond to folic or folinic acid may show an abundance of these growth factors in the blood and urine. Their response to test doses is also 
variable and unhelpful in the diagnosis of deficiency.

At present the therapeutic test remains the best method of detecting folic acid deficiency. If the patient is anaemic one gives first cyanocobalamin and then folic acid, measuring the reticulocyte response by the method already described. If the anaemia does not respond to cyanocobalamin but does respond to folic acid, a folic acid deficiency may be presumed. Of course, if the preliminary test with cyanocobalamin is not made, a response to folic acid does not justify a diagnosis of folic acid deficiency.

Folic acid deficiency may sometimes be recognised even in the absence of anaemia, e.g. a patient with idiopathic steatorrhoea presented with severe pain in the tongue which was covered with deep ulcers. She had become pregnant and was taking mineral and vitamin supplements including cyanocobalamin but not folic acid. Administration of folic acid led to dramatic relief of pain and to healing of the ulcers within a few days. At this time the patient had no anaemia.

\section{Early Diagnosis of Cyanocobalamin De- ficiency in the Absence of Anaemia}

Clinical manifestations of cyanocobalamin deficiency, however caused, may be preceded by a stage when serum cyanocobalamin levels are low, although clinical, neurological, lingual or haematological evidence of such a deficiency may be absent. An abundance of folic acid in the diet, for example of vegans, may accentuate the tendency to neurological manifestations of cyanocobalamin deficiency affecting the spinal cord, brain or optic nerves. For example, a vegan whose diet is rich in folic acid showed no haematological manifestations even when her vision was failing from optic atrophy, and the electroencephalogram was abnormal. When regular cyanocobalamin injections were given the scotomata shrank and the serum cyanocobalamin rose to high normal levels (Ungley, 1957).

Glossitis is another manifestation of cyanocobalamin deficiency which may occur in the absence of haematological manifestations. The above mentioned vegan periodically had sore tongue and the lingual papillae were atrophied. Soreness was relieved by cyanocobalamin injections.

A patient with pernicious anaemia had periodic sore tongue for many years before he developed severe optic atrophy and long before he became anaemic. Even when he had already developed large scotomata with advanced optic atrophy his haemoglobin was 86 per cent. (12.7 gm. per 100 ml.) but by then his red blood count had fallen to 3.77 mils per c.mm. The electroence- phalogram was dominated by excessive slow theta activity and became normal after cyanocobalamin. Moreover the scotomata shrank dramatically after cyanocobalamin (Ungley, 1957).

\section{Addisonian Pernicious Anaemia}

The lesion is an atrophy or atrophic gastritis of the corpus region of the stomach. Once the patient has pernicious anaemia the lesion is irreversible. Because of the resulting loss of intrinsic factor the patient is unable to absorb enough cyanocobalamin from foods (except perhaps from whole liver) to maintain health.

Sometimes the presenting symptoms refer to the nervous system, e.g. paraesthesiae, difficulty in walking or even mental changes with alteration in the psychometric behaviour and in the encephelogram. There may be failure of word discrimination (Ungley, 1957). Occasionally there is a scotoma (' blind spot ') in the centre of each visual field.

All these manifestations of cyanocobalamin deficiency may occur before there are abnormalities in the blood or marrow although the serum cyanocobalamin values will probably be low. In doubtful cases the gastric juice should be examined for free hydrochloric acid after administration of histamine by injection and alcohol by mouth. The important point, however, is to be prepared for the occurrence of vitamin $B_{12}$ deficiency from any cause.

Loss of weight is sometimes observed but seldom noticed early.

Sore tongue can be caused by many other deficiencies but can be due solely to lack of cyanocobalamin, even when there is little or no anaemia (Adams, 1957).

\section{Routes and Agents}

Cyanocobalamin should be given by intramuscular injection. It may seem rational to replace the intrinsic factor with a preparation containing this factor and the vitamin. In fact, however, such preparations are expensive, wasteful and inefficient. Even when the blood counts rise fairly quickly, the level of cyanocobalamin in the serum rises slowly.

Injection intramuscularly avoids the 'intestinal barrier' against cyanocobalamin. High serum levels are achieved quickly, and tissue reserves are rapidly restored.

The maximum rate of increase of red blood cells and packed cell volume in 15 days will be achieved by a single dose of 100-250 $\mu \mathrm{g}$. Even $250 \mu \mathrm{g}$. injected daily does not increase the rate.

But once the therapeutic tests are concluded, it is wise to restore tissue reserves of cyanocobalamin quickly by giving, say, 3 to 5 injections 
each of $1,000 \mu \mathrm{g}$. This is worth while even although a large part of every dose escapes in the urine. Thereafter 200 to $250 \mu \mathrm{g}$. a month may be given, or even $250 \mu \mathrm{g}$. every one or two weeks if serious neurological, mental or visual manifestations are present.

After six months, a permanent regime of $250 \mu \mathrm{g}$. a month may be adopted.

\section{Folic and Folinic Acid}

Neither of these agents is indicated in pernicious anaemia. Even if $40 \mathrm{mg}$. a day is given in addition to full doses of cyanocobalamin, the rate of blood regeneration does not exceed that achieved by giving full doses of cyanocobalamin alone.

If folic or folinic acid is given only, the level of cyanocobalamin in the blood remains low. Neurological symptoms may get worse.

\section{Treatment of Subacute Combined Degeneration}

The immediate urgency, once the diagnosis is established, is to start treatment with large enough doses of cyanocobalamin. Great care must be taken to treat infection of the urinary bladder, damage to the feet, decubitus ulcers, etc.

\section{Iron}

In Addisonian pernicious anaemia the serum iron in relapse is usually high but falls within a few days after therapy. The mean corpuscular haemoglobin concentration is normal.

In many patients the excess of iron which accumulates in the tissues during relapse is enough to prevent iron deficiency from developing even during the rapid remission induced by therapy with cyanocobalamin. Even if the stores of iron are insufficient for complete remission, giving iron while the marrow is megaloblastic is in my experience without effect on the haemoglobin concentration, probably because it cannot be utilised at this stage. Later, when the rate of increase of red blood cells is stepped up, the mean corpuscular haemoglobin concentration may fall and the serum iron level will be below normal. Then oral iron therapy may be given for a few weeks. It should be discontinued when the mean corpuscular haemoglobin concentration has risen and if the serum iron remains normal without iron therapy. Continuation of iron for long periods may carry the risk of loading the tissues with an excess of iron.

In non-addisonian megaloblastic anaemias, e.g. in pregnancy or sprue, a concurrent deficiency of iron is common and partly accounts for the low mean cell volume often found in these disorders.

\section{Antibiotics}

These are not indicated in pernicious anaemia. If given orally they may destroy intestinal microorganisms which have the power to bind intrinsic factor, but the need for this factor still exists unless the cyanocobalamin is given by intramuscular injection (as it should be).

\section{Gastritis and Carcinoma in Addisonian Pernicious Anaemia}

Now that most of the manifestations of cyanocobalamin deficiency can be eliminated the greatest danger of pernicious anaemia is the development of carcinomatous changes in the stomach. Carcinoma may arise either in the atrophic corpus region or in the non-atrophic pylorus region.

Every patient with this disorder has gastritis or gastric atrophy and the incidence of carcinoma of the stomach is much higher than in other members of the population. This is true of pernicious anaemia even during remission. Gastric cytology should be examined after washing out the stomach (Henning and Witte, 1957; Schade, 1957). If it is abnormal during relapse, it may become normal in remission, because changes very like carcinoma occur in gastric cells during relapse. Most patients in remission are free from gastric symptoms. If they have dyspepsia, then they may be given a mixture of hydrochloric acid and pepsin. Theoretically, they should be advised to avoid gastric irritants such as tobacco, aspirin and alcohol, to chew food thoroughly and to eat slowly. The stools may be examined for occult blood, e.g. if gastric symptoms persist or if there is unexplained loss of weight. A barium meal may be given, but is less likely to be succeissful in demonstrating an early carcinoma. Gastroscopy is occasionally successful if the lesion is a polypoid adenoma or adeno-carcinoma. Gastric cytology of stomach washings is the most likely method of demonstrating an early carcinoma. Even at operation the lesion may be difficult to see macroscopically (Schade, 1957).

\section{Objects of therapy in pernicious anaemia}

To summarise, these are:

I. To restore normal haematological findings. Quite small amounts of cyanocobalamin are needed. Doses as small as ro $\mu \mathrm{g}$. a fortnight may be enough to achieve normal values although doses twenty times as much may be needed to achieve a maximum rate of increase of red blood cells and packed cell volume in 15 days. (Ungley and Campbell, 1949, and Ungley and Campbellunpublished.)

2. To reverse or to arrest neurological, cerebral, visual and auditory manifestations. This requires maximum dosage (Ungley, 1957). 
3. Restoration of normal serum levels of cyanocobalamin. This requires moderate doses, but excess is not harmful.

4. Restoration of normal levels of cyanocobalamin to the tissues including the liver. Large doses are required and may be given in the first month of treatment. Mollin and Ross (1953) suggested 3 to 5 doses of $1,000 \mu \mathrm{g}$.

5. For maintenance $200-250 \mu \mathrm{g}$. may be given every 2 or 4 weeks, depending on the condition of the patient.

\section{Megaloblastic Anaemia following Gastrectomy}

Tests with radioactive cyanocobalamin show that after total gastrectomy there is as complete a lack of Castle's intrinsic factor as in pernicious anaemia. The patient, however, does not become anaemic at once. It may take several years to exhaust the stores of cyanocobalamin in the liver and other tissues; many patients never show outward signs of deficiency. Some surgeons now give cyanocobalamin prophylactically-say 200 or $250 \mu \mathrm{g}$. a month. If the patient already has megaloblastic anaemia, then treatment should be as for pernicious anaemia.

Megaloblastic anaemia after partial gastrectomy and gastroenterostomy is sometimes accompanied by steatorrhoea. Intestinal hurry or delay and infection in the small intestine may be responsible. Occasionally the anaemia responds to folic acid but not to cyanocobalamin.

\section{Dietary Cyanocobalamin Deficiency in Vegans and Others}

In temperate climates nutritional megaloblastic anaemias are uncommon. Some examples are given in Ungley (1933 and 1938). In Holland, Nieweg (1953) describes two examples due to low protein diets prescribed for renal disorder.

In Great Britain, Wokes (1954) studied cyanocobalamin deficiency in vegans, i.e. persons living on completely vegetarian diets, without even milk, butter, cheese or eggs. One had sub-acute combined degeneration which responded to cyanocobalamin (Badenoch, 1955). About a dozen had severe mental or nervous symptoms. Sore tongue or paraesthesiae occurred in about a quarter. None had frank megaloblastic anaemia, perhaps because the intake of folic acid was high. Serum cyanocobalamin values were below $100 \mu \mathrm{g} / \mathrm{ml}$. in patients who had been more than six years on the diet.

In a woman vegan, whose serum cyanocobalamin levels were low, central scotomata were almost abolished and virtually normal vision was restored by injection of the vitamin (Ungley, 1957).

Dysphagia at the pharyngo-oesophageal junction, attributed to chronic iron deficiency in a woman, was associated with hypochlorhydria and megaloblastic anaemia, which responded to yeast (Ungley, 1933, fig. 3).

\section{Megaloblastic Anaemia associated with the Fish Tapeworm}

Few people who harbour the fish tapeworm develop megaloblastic anaemia. If the worm is living high up in the small intestine, it may compete with the host for cyanocobalamin in food. The worm itself is a rich source of cyanocobalamin.

The incidence and character of neurological disorders are similar to those in pernicious anaemia. Free hydrochloric acid is usually present in the gastric juice.

The anaemia can be abolished by giving cyanocobalamin by injection, or sometimes by mouth, or by eliminating the worm. An excellent account of this disorder is given by von Bonsdorff (1957).

\section{Megaloblastic Anaemias with Sprue and other Malabsorption Syndromes}

There are several entities included here:

(a) Classical tropical sprue in India may be accompanied by megaloblastic anaemia which in some patients at least has responded to cyanocobalamin.

(b) Nutritional megaloblastic anaemias accompanied by diarrhoea and associated with dietary deficiency, are often loosely labelled as 'tropical sprue' in the Southern United States and in Cuba. They usually respond to cyanocobalamin.

(c) Idiopathic steatorrhoea in non-tropical climates may be accompanied by megaloblastic anaemia. Even if there is no diarrhoea this diagnosis must be considered, especially if the blood picture shows little or no macrocytosis, or if the response to cyanocobalamin is poor or absent. Patients who fail to respond to this agent respond to folic acid, but not all of them attain normal blood values even after long treatment.

Cerebral, spinal or neurological disorders occasionally develop during therapy with folic acid; sometimes these can be relieved or arrested by administering cyanocobalamin. Cloake, Cooke and Hall (1954) describe 18 patients with a variety of neurological disorders associated with steatorrhoea. None had all the essential characteristics of subacute combined degeneration of the cord. The results of treatment with cyanocobalamin and other $B$ vitamins varied unaccountably. This is also our experience (Ungley, 1955). A special diet with supplements is often required because of malabsorption of other nutrients.

\section{Megaloblastic Anaemias and Intestinal Stricture or Culs-de-sac}

Usually the blind loop is self-filling and becomes 
infected. A haematopoietic response to antibiotics given orally has been observed, but it is usually partial. Although there is usually no loss of intrinsic factor, there may be a response to cyanocobalamin by injection after oral administration of the vitamin with intrinsic factor has failed. In some patients the anaemia is completely refractory to cyanocobalamin, but responds to folic acid. There may be steatorrhoea and other evidence of a malabsorption syndrome. Some patients are relieved by operations designed to prevent stagnation of intestinal contents.

\section{Megaloblastic Anaemia and Epilepsy}

Some patients with epilepsy who have been treated with primidone, phenytoin and phenobarbitone have developed megaloblastic anaemia. Girdwood and Lenman (1956) suggest that these drugs may act as competitive inhibitors of some enzyme system which utilises folic acid as a cofactor. In some cases there was dietary deficiency. The patients may have free hydrochloric acid in the gastric juice and some of them respond to folic acid rather than to cyanocobalamin.

\section{Megaloblastic Anaemia in Liver Damage}

In most cases of macrocytic anaemia in liver diseases with protein malnutrition the marrow is normoblastic or macronormoblastic (Woodruff, 1955). Occasionally with liver cirrhosis there is a megaloblastic marrow, as in a patient described by Movitt (1950), whose anaemia responded normally to $150 \mu \mathrm{g}$. of cyanocobalamin. Nieweg (1953) believes that deficient intake of haematopoietic factors is responsible, rather than deficient storage.

\section{Tropical Megaloblastic Anaemias}

These anaemias, whether associated with pregnancy or not, commonly arise in persons taking a deficient diet. Some respond to cyanocobalamin and some to folic acid. Many have diarrhoea, helminth infestation or malaria, which influence the absorption or utilisation of haematopoietic factors.

The response to cyanocobalamin or to folic acid varies in different parts of India, perhaps due to dietary differences.

\section{Megaloblastic Anaemia in Children}

This is a mixed group. Infants may become anaemic after an infection or from deficiency of folic acid in the milk, which may be breast milk, cows' milk or even goats' milk. The mothers are not always anaemic. The anaemia is often refractory to cyanocobalamin but responds to folic acid.

A similar megaloblastic anaemia was produced experimentally in scorbutic monkeys, which responded to folic acid.

Malabsorption syndromes may be discovered in children of any age with megaloblastic anaemia. The anaemia may respond either to cyanocobalamin or to folic acid.

Megaloblastic anaemia in childhood may be the initial manifestation of Addisonian pernicious anaemia, as in a child whose father had pernicious anaemia (Mollin, Baker and Doniach, 1955).

\section{Megaloblastic Anaemia of Pregnancy and the Puerperium}

In the tropics this is mainly due to chronic dietary deficiency of folic acid or cyanocobalamin. In any country it may be discovered in patients who already have Addisonian pernicious anaemia or idiopathic steatorrhoea, the pregnancy providing an additional strain on already depleted reserves.

But megaloblastic anaemia of pregnancy and the puerperium in non-tropical countries may exist as a separate entity. Dietary deficiency is common but not invariable. There is a seasonal incidence in the winter or spring (Thompson, 1957, Forshaw, 1957); but some diets are normal and many patients taking grossly inadequate diets do not develop a megaloblastic marrow. Free hydrochloric acid is usually present in the gastric juice, but it may be temporarily absent during pregnancy.

The red cells are not necessarily large; the mean cell volume may even be below normal and mean cell diameter may also be small. The only certain way to find out is to do a marrow biopsy or to find megaloblasts in the peripheral blood, e.g. by staining the white cell-platelet layer. This is a doubtful alternative, and once treatment has been given the marrow will be useless for diagnosis. The frequency with which megaloblastic anaemia of pregnancy is diagnosed depends on the frequency with which the observer uses marrow puncture.

Most patients in this country respond to folic acid rather than to cyanocobalamin. In Eire and in America, however, many of the patients respond to cyanocobalamin, and the rest to folic acid. If the anaemia is discovered during pregnancy, the response to the therapy may be slow. The remission goes ahead more rapidly in the puerperium. But often the anaemia is not discovered until a few days after the puerperium and very severe relapse may have taken place. Exchange transfusion may be necessary.

The safest remedy is folic acid, but a test for serum cyanocobalamin may be undertaken. Our results, and those of most others, show normal values.

Folic acid may be given parenterally or orally in doses of about $40 \mathrm{mg}$. a week. Cyanocobalamin, 
if indicated, may be injected in doses of $250 \mu \mathrm{g}$. once a week.

In pregnancy once remission is under way some iron, parenterally if necessary, may be given. After the puerperium iron may be given orally.

Lowenstein, Pick and Philpott (1955) have had no further cases of megaloblastic anaemia of pregnancy and the puerperium since they gave daily prophylactic doses of $3.0 \mathrm{mg}$. folic acid and $4.5 \mu \mathrm{g}$. cyanocobalamin daily.

\section{BIBLIOGRAPHY}

ADAMS, J. F. (1957), Lancet, i, I 120.

BADENÓCH, J. (I 955), Proc. roy. Soc. Med., 47, 426

CLOAKE, P. C. P., COOKE, W. T., and HALL, G. S. (1954), Quart. F. Med., 23, 462

FORSHAW, J. W. B. (1957), Lancet, i, 1249

GIRDWOOD, R. H. (1956), Quart. F. Med., 25, 87

GIRDWOOD, R. H., and LENMAN, J. A. R. (1956), Brit. med. 7 . i, 146

HENNING, N., and WITTE, S. (1957), 'Atlas der Gastroenterologischen Cytodiagnostik.' Translated by R. O. K. Schade, pp. ro3, Georg Thieme, Stuttgart.
LOWENSTEIN, L., PICK, C., and PHILPOTT, N. (r955), Amer. F. Obstet. Gynec., 70, 1309.

MOLLIN, D. L., BAKER, S. J., and DONIACH, I. (1955), Brit. F. Haematol., i, 278.

MOLLIN, D. L., and ROSS, G. I. M. (1953), Brit. med. F., ii, 640.

MOVITT, E. R. (1950), Blood, 5, 468. NIEWEG, H. O. (1953),' 'Vitamine $B_{12}$ en Foliumzuurdeficientie ':
Uitgeverij Excelsior's Gravenhage.

SCHADE, R. O. K. (r957), Demonstration to British Medical Association, Annual Meeting in Newcastle upon Tyne, June, 1957. See also Book Review of 'Cytology of Digestive System, Lancet, $1957,2,5 \mathrm{I}$.

THOMPSON, R. B. (1957), Lancet, i, I 17 r.

UNGLEY, C. C. (r933),Quart. F. Med., 2, $38 \mathrm{r}$.

UNGLEY, C. C. (1938), Lancet, i, 875, 925, $98 \mathrm{I}$.

UNGLEY, C. C. (1955), Vitam. and Horm., $13,137$.

UNGLEY, C. C. (1957), in 'Vitamin $B_{12}$ and Intrinsic Factor,' p. 474, Ferdinand Enke, Stuttgart.

UNGLEY, C. C., and CAMPBELL, H. (1949), Brit. med. $\mathcal{Y}$., ii, I370.

UNGLEY, C. C., and CAMPBELL, H. Unpublished.

VON BONSDORFF, B. (1957), in 'Vitamin $B_{12}$ and Intrinsic Factor,' p. 3 I I, Ferdinand Enke, Stuttgart.

WOKES, F. ( 1954$)$, Lancet, ii, 383.

WOODRUFF, A. W. (1955), Brit. med. F., i, 1297.

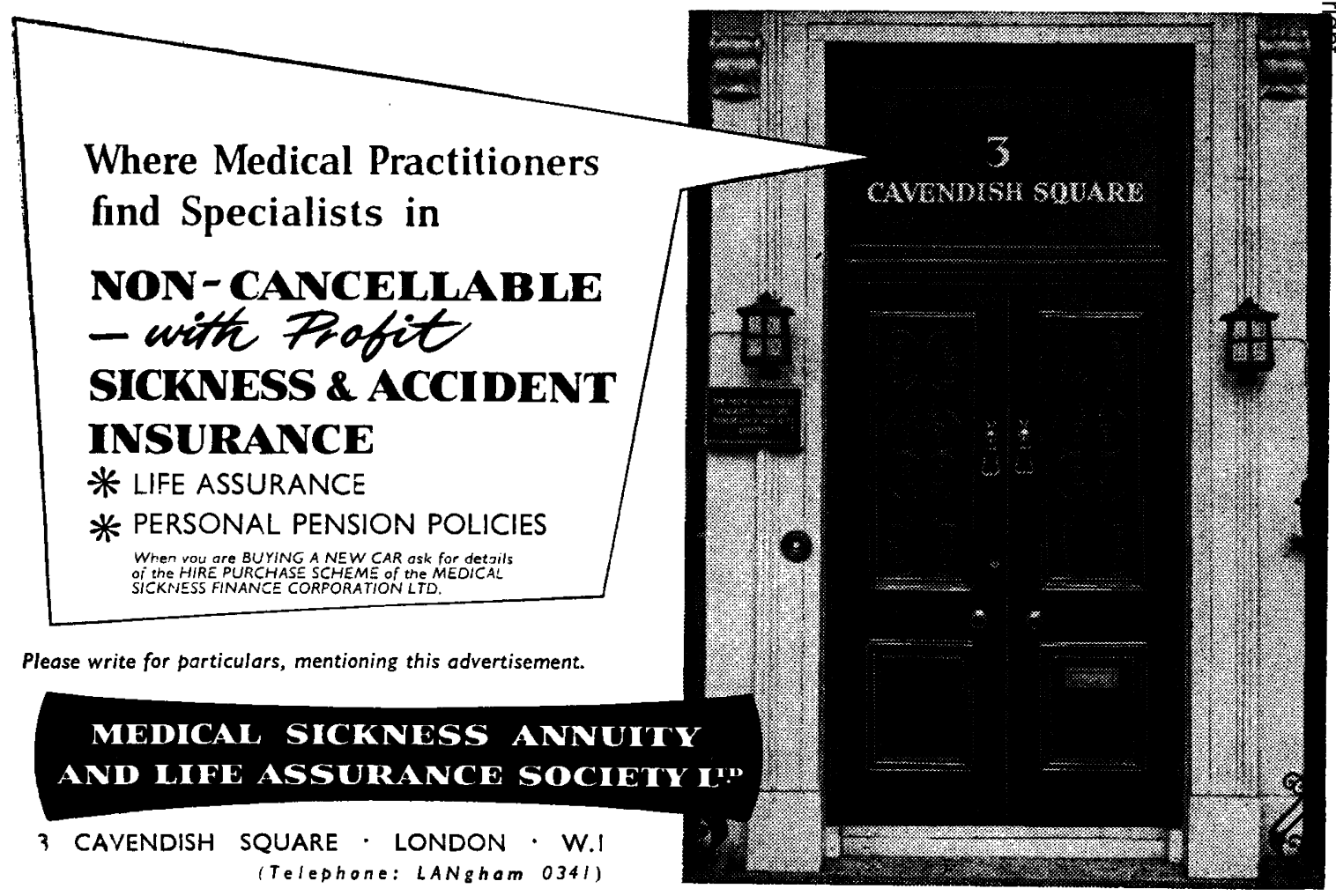

